\title{
Evaluation of Marginal Adaptation of MTA, Biodentine, and MTA Plus as Root-End Filling Materials-An SEM Study
}

\author{
Nishant Sharma ${ }^{1}$ \\ 1Department of Conservative Dentistry and Endodontics, Guru \\ Nanak Dev Dental College, Sunam, Punjab, India
}

Rajinder Bansal ${ }^{1}$ Manu Bansal ${ }^{1} \quad$ Mandeep Singh Matta ${ }^{1}$ Shilpa Walia ${ }^{1}$ Baljeet Kaur ${ }^{1}$

\begin{abstract}
Address for correspondence Rajinder Bansal, MDS, Department of Conservative Dentistry and Endodontics, Guru Nanak Dev Dental College, Patiala 148028, Punjab, India (e-mail: drrajinderbansal@hotmail.com).
\end{abstract}

\begin{abstract}
Keywords

- Biodentine

- MTA

- MTA plus

- root-end filling

- scanning electron

microscope

Objective This study aimed to evaluate adaptation of mineral trioxide aggregate (MTA), Biodentine, and MTA Plus when used as root-end restorative materials using scanning electron microscope.

Materials and Methods Forty-five extracted teeth with one root canal were cleaned and sectioned at cementoenamel junction, maintaining a standardized length of $15 \mathrm{~mm}$. Chemomechanical preparation and obturation was done in all the samples, and access was restored with glass ionomer cement (GIC). Root-end cavities were prepared in all the samples after 3-mm apical root end was resected. Forty-five samples were divided into three groups with 15 samples each. Root apices were filled with ProRoot MTA in group I, Biodentine in group II, and MTA Plus in group III. The sample teeth were sectioned for examination of gaps at the margins using scanning electron microscope. The data collected were put to statistical analysis by one-way ANOVA (analysis of variance) and post hoc tests.

Results The minimum margin gap score of $2.44 \mu \mathrm{m}$ was observed in group II (Biodentine), whereas maximum gap score of $5.63 \mu \mathrm{m}$ was observed in group I (ProRoot MTA); $4.92 \mu \mathrm{m}$ mean margin gap score was observed in group III (MTA Plus). Conclusion Biodentine showed least margin gap at the interface, so it can be considered as the best root-end filling material, whereas, MTA Plus can be considered as a substitute to ProRoot MTA as a root-end filling material.
\end{abstract}

\section{Introduction}

The goal of endodontic treatment is to hermetically seal all the links between root canal space and periradicular tissues forming a fluid tight seal. ${ }^{1}$

Endodontic treatment is a conservative and nonsurgical treatment. In cases such as calcified root canals, severely dilacerated roots, and separated instruments in root canals, surgical endodontic therapy is often required for saving the tooth. ${ }^{2}$

An endodontic surgery includes root apex exposure after hard and soft tissue removal, periradicular curettage if required, root-end resection, and preparation of root end, followed by sealing of root end with a restoration. ${ }^{3}$

Root-end filling material does not allow bacteria and bacterial products from root canal to pass into periapical

received

December 26, 2018

accepted

January 4, 2019

published online

April 4, 2019 tissues and vice versa. ${ }^{4}$ Materials such as amalgam, intermediate restorative material (IRM), glass ionomer cement, composite resin, and carboxylate cement have been used for the same. $^{5}$

In 1993, mineral trioxide aggregate (MTA) was developed as endodontic material by Dr. Torabinejad at Loma Linda University, California, United States. It was approved for use in endodontics by the U.S. Food and Drug Administration (FDA) in 1998 (ProRoot MTA, Dentsply Tulsa dental, Tulsa, Oklahoma, United States). MTA consists of tricalcium silicate, tricalcium aluminate, dicalcium silicate, calcium sulfate (present in hemi-hydrate and anhydrate form), and bismuth oxide. ${ }^{6}$ It is used in clinical endodontics for procedures such as pulp capping, root-end filling, repair of furcation perforations, apexification, and for obturation. ${ }^{7}$
(C)2019 Bhojia Dental College and Hospital affiliated to Himachal Pradesh University
License terms

$10.1055 / \mathrm{s}-0039-1684154$ ISSN 2321-1482. 
Some clinical problems with MTA include discoloration, handling difficulty, longer setting time, presence of toxic elements in the composition, and high material cost, and there is no known solvent making its removal from the root canal after setting very difficult. ${ }^{8}$

In 2010, a bioactive cement, Biodentine (Septodont, Saint-Maur-Des-Fosses, France) also known as smart dentin replacement was introduced by Gilles and Olivier. ${ }^{9}$ Manufacturer claimed several advantages of Biodentine such as ease of manipulation, shorter setting time, tissue regeneration, early mineralization, better consistency, greater bond strength, acid resistance, elastic modulus being similar to dentine, and more biocompatibility. ${ }^{10}$ Hence, it can be used for dentin replacement in crown besides endodontic repair material such as MTA. It has indications for root-end filling, repair of perforations, apexification, and direct and indirect pulp capping. Certain drawbacks of Biodentine were less wear resistance, less radio-opacity when compared with MTA, and poor flexural strength. ${ }^{11}$

In 2012, MTA Plus came to dental market (Avalon Biomed, Houston, Texas, United States). MTA Plus has composition similar to MTA but has finer particle size and has a greater surface area, which results in shorter setting time than MTA. ${ }^{7}$

Microleakage occurring at the interface between dentin and root-end restoration is the key determinant for successful periapical surgery. Methods for detecting the microleakage include dye penetration, fluid filtration, dye extraction or dissolution method, bacteria or toxin infiltration method, electrochemical method, reverse diffusion method, use of radioisotopes and metal solution tracers, and microscopic methods such as scanning electron microscope (SEM), confocal microscope, and transmission electron microscope. ${ }^{12}$

SEM visualizes the adaptation of restoration to cavity margins because of its good depth of focus and higher magnification. ${ }^{13}$ It also allows better visualization of irregular root-dentin structures, with different heights, without altering the focus, and generates data in digital form. ${ }^{14}$

Henceforth, this study was planned for evaluating the gaps at the margins MTA, Biodentine, and MTA Plus when used as root-end filling materials using SEM.

\section{Materials and Methods}

Forty-five teeth with closed apices without any visible evidence of root fracture, cracks, and external resorption were selected for this study. All the tooth surfaces were cleaned with No. 15 bard parker blade. They were then immersed in $5 \%$ sodium hypochlorite solution for disinfection overnight and then stored in $0.2 \%$ thymol (NICE, Coimbatore, Tamil Nadu, India).

The crowns of all the selected teeth were sectioned from the roots to standardize the root length to $15 \mathrm{~mm}$. Size 10k file (Mani inc, Takenzawa, North of Tokyo, Japan) was put into the root canal until it was seen at the apex, and then $0.5 \mathrm{~mm}$ was subtracted from that point to establish final working length. Root canal preparation was completed with step-back technique up to ISO 40 apical size using manual K-files (Mani, Inc., Japan) in all the samples.

The canals were thoroughly irrigated with alternate use of 5\% sodium hypochlorite (5\% Hyposol, Pervest Denpro Ltd.,
Jammu, India) and 17\% ethylene diamine-tetraacetic acid solution (Pervest Denpro, Jammu, India). A final irrigation with normal saline was done to eliminate or neutralize the effects of sodium hypochlorite. Absorbent paper points were used to dry canals, and obturation was done with matching gutta-percha points (Dentsply) and Sealapex sealer (SybronEndo, Orange, California, United States) using cold lateral compaction technique. Glass ionomer cement (GC Fuji IX GC Asia, Singapore) was used to restore access cavity. Samples were then stored in $100 \%$ humidity until use.

The $3 \mathrm{~mm}$ of all roots was resected using straight fissure diamond bur from apex, making sure the resection is perpendicular to long axis of the tooth. This was followed by preparation of retrograde cavities in root canal exit on resected root surface using round diamond bur in slow speed handpiece. All prepared roots were divided in three groups having 15 teeth each depending on the material used for root-end filling:

\section{Group I: ProRoot MTA (Dentsply Maillefer, Switzerland)}

Group II: Biodentine

Group III: MTA Plus (Pervest Denpro Ltd., Jammu, India)

Group I: ProRoot MTA was used in this group. It is packaged in powder liquid form. The powder was dispensed on one side of pad and liquid was squeezed next to the powder, maintaining powder-liquid ratio 3:1 ratio and mixed according to the manufacturer's instructions.

The material was mixed until all the powder particles were hydrated and material turned into a thick, creamy, and putty-like consistency. Then it was filled into the prepared root-end cavity using MTA carrier (GDC, Hoshiarpur, Punjab, India) and thoroughly condensed with the help of hand plugger 5/7 (API, Delhi, India). Root end was left in contact with moist cotton for 4 hours to ensure complete setting of ProRoot MTA.

Group II: In each sample of this group, Biodentine was used as a retrograde filling material. It is available as powder liquid system.

Biodentine capsule-containing powder was opened and placed in a capsule holder of mechanical triturator (Dentsply Maillefer). Then five drops of liquid was poured into the capsule, and mixing was performed for approximately 30 seconds until the material turned into thick putty-like consistency as recommended by the manufacturer. It was then carried in the prepared cavity, thoroughly condensed with the help of hand plugger $5 / 7$, and allowed to set for 12 minutes to ensure complete setting.

Group III: In each sample of this group, MTA Plus was used as a retrograde filling material. It is available as powder and gel system.

MTA Plus powder and a small drop of gel were put onto the slab. The mixing of powder and gel was performed for about 1 minute using mixing spatula until the material turned into thick, creamy putty-like consistency, which was filled into the prepared root-end cavity with MTA carrier. The material was then thoroughly condensed in the prepared cavities with the help of hand plugger 5/7. Root end was then covered with moist cotton for 1 hour to allow complete setting of MTA 
Plus. Radiographs confirmed the quality of root-end filling of all the samples from the three groups.

All the prepared samples were then incubated at $37^{\circ} \mathrm{C}$ and $100 \%$ humidity for 24 hours. Each sample was then sectioned longitudinally along the long axis of the tooth using diamond disc in micromotor contra-angled handpiece (NSK, Confident Dental Equipment, New Delhi, India). The gap at interface of dentin and root-end filling materials was measured in micrometers using SEM in all the three groups, and 30 readings were recorded for each sample. The average of these 30 readings was taken as a mean marginal gap of that particular sample. The data thus obtained were recorded and put under statistical analysis.

\section{Results}

The mean marginal gap obtained at the interface of dentine rootend filling materials was recorded to be minimum in group II (Biodentine), that is, $2.44 \mu \mathrm{m}$, whereas the mean marginal gap obtained for group I (ProRoot MTA) was found to be maximum, that is, $5.63 \mu \mathrm{m}$. The mean marginal gap obtained for group III (MTA Plus) was found to be $4.92 \mu \mathrm{m}$ ( -Fig. 1). When compared statistically using one-way ANOVA (analysis of variance) test, the difference in mean marginal gap between three groups was found to be highly significant $(p<0.001)(-$ Table 1$)$.

Group I in which root-end preparation was restored with ProRoot MTA had mean marginal gap of $5.63 \mu \mathrm{m}$ whereas

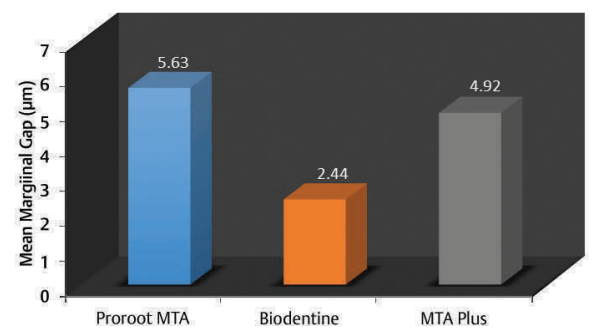

Fig. 1 Bar graph showing comparison of mean marginal gap in three groups. MTA, mineral trioxide aggregate.

in group II in which root-end preparation was restored with Biodentine had mean marginal gap of $2.44 \mu \mathrm{m}$. When compared statistically, this difference in mean marginal gap between the two groups was highly significant $(p<0.001)$. Group II in which root-end preparation was restored with Biodentine had mean marginal gap of $2.44 \mu \mathrm{m}$ whereas in group III in which root-end preparation was restored with MTA Plus had mean marginal gap of $4.92 \mu \mathrm{m}$. When compared statistically, this difference in mean marginal gap between the two groups was highly significant $(p<0.001)$. Group I in which root-end preparation was restored with ProRoot MTA had mean marginal gap of $5.63 \mu \mathrm{m}$ whereas in group III in which root-end preparation was restored with MTA Plus had mean marginal gap of $4.92 \mu \mathrm{m}$. When compared statistically, this difference in mean marginal gap between the two groups was statistically insignificant $(p>0.05)(-$ Table 2$)$.

Table 1 One-way statistical analysis

\begin{tabular}{|c|c|c|c|c|c|c|c|c|}
\hline \multicolumn{9}{|l|}{ Descriptive gap } \\
\hline & \multirow[t]{2}{*}{$N$} & \multirow[t]{2}{*}{ Mean } & \multirow[t]{2}{*}{ SD } & \multirow{2}{*}{$\begin{array}{l}\text { Standard } \\
\text { error }\end{array}$} & \multicolumn{2}{|c|}{$95 \% \mathrm{Cl}$ for mean } & \multirow[t]{2}{*}{ Minimum } & \multirow[t]{2}{*}{ Maximum } \\
\hline & & & & & Lower bound & Upper bound & & \\
\hline $\begin{array}{l}\text { Group I } \\
\text { (ProRoot MTA) }\end{array}$ & 15 & 5.6330420 & 2.17240401 & 0.56091230 & 4.4300048 & 6.8360792 & 2.94400 & 12.05230 \\
\hline $\begin{array}{l}\text { Group II } \\
\text { (Biodentine) }\end{array}$ & 15 & 2.4444880 & 0.94871556 & 0.24495730 & 1.9191068 & 2.9698692 & 0.94017 & 3.90463 \\
\hline $\begin{array}{l}\text { Group III } \\
\text { (MTA Plus) }\end{array}$ & 15 & 4.9216947 & 1.41883646 & 0.36634200 & 4.1359692 & 5.7074201 & 1.57940 & 7.36443 \\
\hline Total & 45 & 4.3330749 & 2.08295127 & 0.31050804 & 3.7072870 & 4.9588627 & 0.94017 & 12.05230 \\
\hline
\end{tabular}

Abbreviations: $\mathrm{Cl}$, confidence interval; MTA, mineral trioxide aggregate; SD, standard deviation.

Table 2 Post hoc tests

\begin{tabular}{|l|l|l|l|l|l|l|}
\hline Multiple comparisons dependent variable: gap Tukey HSD \\
\hline \multirow{2}{*}{$(\mathrm{I})$ group } & (J) group & Mean difference (I-J) & Standard error & Sig. ( $p$-value) & \multicolumn{2}{l|}{$95 \% \mathrm{Cl}$} \\
\cline { 3 - 7 } & & & & Lower bound & Upper bound \\
\hline \multirow{2}{*}{ ProRoot MTA } & Biodentine & $3.18855400^{\text {a }}$ & 0.58242776 & $<0.001^{\text {b }}$ & 1.7735494 & 4.6035586 \\
\cline { 2 - 7 } & MTA Plus & 0.71134733 & 0.58242776 & 0.447 & -0.7036573 & 2.1263520 \\
\hline \multirow{2}{*}{ Biodentine } & ProRoot MTA & $-3.18855400^{\text {a }}$ & 0.58242776 & $<0.001^{\text {b }}$ & -4.6035586 & -1.7735494 \\
\cline { 2 - 7 } & MTA Plus & $-2.47720667^{\text {a }}$ & 0.58242776 & $<0.001^{\text {b }}$ & -3.8922113 & -1.0622020 \\
\hline MTA Plus & Biodentine & $2.47720667^{\text {a }}$ & 0.58242776 & $<0.001^{\text {b }}$ & 1.0622020 & 3.8922113 \\
\cline { 2 - 7 } & ProRoot MTA & -0.71134733 & 0.58242776 & 0.447 & -2.1263520 & 0.7036573 \\
\hline
\end{tabular}

Abbreviations: $\mathrm{Cl}$, confidence interval; HSD, honestly significant difference; MTA, mineral trioxide aggregate.

${ }^{a}$ The mean difference is significant at the 0.05 level

${ }^{\mathrm{b}} p$-value is significant at 0.05 level. 


\section{Discussion}

Nonsurgical root canal therapy includes removal of infected contents of the canal along with irritants, followed by complete sealing of root canal system in three dimensions. ${ }^{15}$ Endodontic therapy failure is caused by apical microleakage. However, cases in which fluid tight seal is not possible by an orthograde approach, for example resorptive root defects, ledges, perforation defects, root canal obstructions, anatomical variations, and separated instruments in the apical region of the tooth, surgical endodontics becomes the only option to save the tooth. ${ }^{16}$

Surgical endodontic therapy includes root-end cavity preparation with appropriate instruments and restoration with a biocompatible root-end filling material. ${ }^{17}$ This procedure seals the root end against microleakage and also stimulates the regeneration of periodontium. ${ }^{17}$

Studies on root-end resection showed that minimum $3 \mathrm{~mm}$ of root-end resection can eliminate $98 \%$ apical ramifications and $93 \%$ of the lateral canals, which are responsible for endodontic therapy failure. ${ }^{18}$

Root-end resection at 30 and 45 degrees to the long axis of the tooth removes more root structure and exposes more dentinal tubules to the periradicular tissues, whereas resection at 90 degrees conserves root structure and exposes less dentinal tubules, also maintaining a better crown/root ratio. ${ }^{19} \mathrm{~A}$ fluid tight apical seal is very important for achieving success in surgical endodontics. ${ }^{20}$ Therefore, it becomes important to seal the root ends with a suitable root-end filling material.

According to Torabinejad et al, an ideal root-end filling material should have ability to adhere to the dentine walls for complete seal of the root canal system. It should be nontoxic, should not irritate periradicular tissues, and promote healing. Also, it must not corrode and should not be electrochemically active. It should have easy manipulation and should be radioopaque. Additionally, it should be dimensionally stable, non-resorbable, and impervious to moisture. ${ }^{21}$

Several restorative materials were used for retrograde filling in the past such as silver amalgam, cavit, zinc oxide eugenol-based cements line IRM and super EBA, glass ionomer cements, modified glass ionomer cements, and composites. The requirements of an ideal root-end filling material are not fulfilled by any of the restorative material. ${ }^{22}$ Amalgam has potential for corrosion and mercury release; also, being moisture sensitive precludes its use as retrograde filling material. ${ }^{23}$ Cavit disintegrates very fast in tissue fluids as it is soluble. Super EBA and IRM are cytotoxic, sensitive to moisture, and difficult to handle. ${ }^{24}$ Glass ionomer cement and composite resin are technique and moisture sensitive, hence difficult to use in endodontic surgical situations. ${ }^{23}$

MTA was developed by Torabinejad et al at Loma Linda University. ${ }^{22}$ It was approved in 1998 for endodontic use by the U.S. FDA (ProRoot MTA, Dentsply Tulsa). ${ }^{25}$ Favorable properties of MTA include excellent sealing ability, biocompatibility, acceptable compressive strength, insolubility in fluids, excellent radio-opacity, and antibacterial effect. ${ }^{26}$ Additionally, it induces hard tissue formation, which includes deposition of cementum and periodontal fiber regeneration. ${ }^{27}$ However, it has several disadvantages such as discoloration potential, difficult handling, long setting time, presence of toxic elements in the material composition, high material cost, absence of known solvent, and difficulty in removal after setting. ${ }^{28}$

Biodentine was introduced in 2010 by Gilles and Olivier.,29 It is available in powder and liquid form. It has less setting time of 12 minutes, easier manipulation, good compressive strength, no effect of blood contamination on the physical properties, and cost-effectiveness. ${ }^{30}$ However, it has many disadvantages such as less wear resistance, less radio-opacity as compared with MTA, and poor flexural strength. ${ }^{11}$

MTA Plus was introduced to dental market in 2012. Manufacturers claim that it has composition similar to MTA but has finer particle size and has a greater surface area, which results in shorter setting time than that of MTA.?

Dye penetration is the most commonly used method for detecting apical leakage, but the disadvantages of this technique are dye dissolving, random sectioning not showing deep dye penetration, dentinal tissue loss with dye, demineralization, and dehydration. ${ }^{31}$ Dye extraction method has the main disadvantage of difficulty of dye to reach the porosity of interface between filling material and root. ${ }^{31}$ Fluid filtration is not a standardized method as there is wide range in time (1-3 hours) and pressure values (1-2 psi). Radioisotope penetration and electrochemical penetration techniques are complex procedures and are difficult to perform. ${ }^{31}$

SEM visualizes adaptation of restorative materials to cavity margins because of its high magnification and depth of focus. ${ }^{13}$

It allows better visualization of root dentin structures, with different heights, without alternation of the focus, and generates data in digital form. ${ }^{14}$ SEM was used in the present in vitro study to evaluate the margin adaptation of MTA, Biodentine, and MTA Plus when used as root-end filling materials.

In this study, the mean margin gap obtained at the interface of dentine root-end filling materials was recorded to be minimum in group II (Biodentine), that is, $2.44 \mu \mathrm{m}$, whereas the mean margin gap obtained for group I (ProRoot MTA) was determined to be maximum, that is, $5.63 \mu \mathrm{m}$. The mean marginal gap obtained for group III (MTA Plus) was found to be $4.92 \mu \mathrm{m}$. When compared statistically using one-way ANOVA test, the difference in mean marginal gap between the three groups was found to be highly significant $(p<0.001)(-$ Table $\mathbf{1})$.

Group I in which root-end preparation was restored with ProRoot MTA had mean marginal gap of $5.63 \mu \mathrm{m}$ whereas in group II in which root-end preparation was restored with Biodentine had mean marginal gap of $2.44 \mu \mathrm{m}$. When compared statistically, this difference in mean marginal gap between the two groups was highly significant $(p<0.001)$ (-Table $\mathbf{1}$ ).

It was found that Biodentine showed least amount of microleakage as compared with MTA and glass ionomer cement when dye leakage study was performed. ${ }^{32}$ Biodentine also exhibited less microleakage than ProRoot MTA, when compared using dye penetration technique. ${ }^{33}$ When root-end filling materials for margin adaptation were compared using confocal laser scanning microscope, it was found that Biodentine had better marginal adaptation than MTA and glass ionomer cement. ${ }^{34}$ 
When Biodentine comes in contact with dentine, it leads to the formation of "mineral tag" like structures along the interface, called the "mineral infiltration zone." The collagen component of the interfacial dentin is degraded by the alkalinity of the hydration products, resulting in prominent biomineralization leading to better seal. ${ }^{35}$

Physical properties of a material such as adsorption, permeability, strength, density, and sealing ability of a material are severely affected by the porosity. Biodentine exhibits less porosity and pore volume on complete setting when compared with MTA, resulting in better marginal seal and less microleakage. ${ }^{36}$

Group II in which root-end preparation was restored with Biodentine had mean marginal gap of $2.44 \mu \mathrm{m}$, whereas in group III in which root-end preparation was restored with MTA Plus had mean marginal gap of $4.92 \mu \mathrm{m}$. When compared statistically, this difference in mean marginal gap between two groups was highly significant $(p<0.001)$ (-Table 2). When comparing sealing ability of MTA Plus and Biodentine for furcal perforations using spectrophotometry, less dye absorbance with Biodentine was seen than MTA Plus. ${ }^{29}$

Group I in which the root-end preparation was restored with ProRoot MTA had mean marginal gap of $5.63 \mu \mathrm{m}$, whereas in group III in which the root-end preparation was restored with MTA Plus had mean marginal gap of $4.92 \mu \mathrm{m}$. When compared statistically, this difference in mean marginal gap between the two groups was statistically insignificant ( $p>0.05$; - Table 2$)$. Lesser microleakage was seen with MTA Plus than ProRoot MTA when dye leakage study was performed, confirming better seal with MTA Plus. ${ }^{7}$ The chemical composition of ProRoot MTA and MTA Plus was found to be almost similar, but MTA Plus had a finer particle size. ${ }^{37}$ Additionally, MTA Plus had an advantage of the presence of an anti-washout gel that increases its the washout resistance. It was also found that ProRoot MTA, when mixed with water, formed a sandy consistency due to leaching of bismuth in solution, whereas MTA Plus mixed with anti-washout gel had a more viscous and rubbery consistency. This consistency of MTA Plus in cement phase results in high strength. Moreover, anti-washout gel does not affect the radio-opacity of the material and increases its sealing ability by forming a branched polymer network at the interface. ${ }^{37}$

Thus, it can be concluded that Biodentine has least gap at the interface, and it can be considered as the promising rootend filling material. However, MTA Plus and ProRoot MTA showed almost similar gap at the interface. Therefore, MTA Plus can become a possible substitute to ProRoot MTA as a root-end filling material. As our study was performed in in vitro conditions, results obtained cannot be directly extrapolated clinically, but they permit comparison of the similar materials. However, owing to the limitations of the in vitro conditions, further in vivo research is required to evaluate Biodentine as a root-end filling material.

\section{Conclusion}

All the root-end filling materials used in this study, that is, ProRoot MTA, Biodentine, and MTA Plus showed gap at the interface of dentin and root-end filling material. However,
Biodentine showed minimum gap at the interface. Also, MTA Plus and ProRoot MTA had similar interfacial gap on investigation. Hence, MTA Plus can be a substitute to ProRoot MTA as a root-end filling material.

\section{Funding \\ None.}

\section{Conflict of Interest}

None declared.

\section{References}

1 Ozata F, Erdilek N, Tezel H. A comparative sealability study of different retrofilling materials. Int Endod J 1993; 26(4):241-245

2 Holt GM, Dumsha TC. Leakage of amalgam, composite, and super-EBA, compared with a new retrofill material: bone cement. J Endod 2000;26(1):29-31

3 Sauveur G, Boucher Y. A teaching model for endodontic surgery. Int Endod J 1998;31(2):133-136

4 Fogel HM, Peikoff MD. Microleakage of root-end filling materials. J Endod 2001;27(7):456-458

5 Maltezos C, Glickman GN, Ezzo P, He J. Comparison of the sealing of Resilon, Pro Root MTA, and Super-EBA as rootend filling materials: a bacterial leakage study. J Endod 2006;32(4):324-327

6 Camilleri J, Pitt Ford TR. Mineral trioxide aggregate: a review of the constituents and biological properties of the material. Int Endod J 2006;39(10):747-754

7 Saraswathi DD, Tejavath SK, Babu MR, Swetha B, Gandhi B. A comparative evaluation of the sealing ability of three recent root-end filling materials: an in vitro study. J Adv Oral Res 2015;6:33-39

8 Monisha R, Manish R. MTA as a revolution in endodontics-a review. J Dent Med Sci 2013;9:18-21

9 Gilles R, Oivier M, Dental Composition. Patent 2011, WO 2011/124841, US 2013/0025498. Applicant Septodont, SaintMaur-des-Fosses, France

10 Priyalakshmi S, Ranjan M. Review on Biodentine-a bioactive dentin substitute. J Dent Med Sci 2014;13:13-17

11 Pagaria S, Singh BD, Dubey A, Avinash A. Biodentine as a new calcium silicate based cement. Chettinad Health City Med J 2015;4:182-184

12 Muliyar S, Shameem KA, Thankachan RP, Francis PG, Jayapalan CS, Hafiz KAA. Microleakage in endodontics. J Int Oral Health 2014;6(6):99-104

13 Paradella TC, Bottino MA. Scanning electron microscopy in modern dentistry research. Braz Dent Sci 2012;15:43-48

14 Costa AT, Post LK, Xavier CB, Weber JB, Gerhardt-Oliveira M. Marginal adaptation and microleakage of five root-end filling materials:aninvitrostudy.MinervaStomatol2008;57(6):295-300

15 Schilder H. Filling root canals in three dimensions. 1967. J Endod 2006;32(4):281-290

16 Khandelwal A, Karthik J, Nadig RR, Jain A. Sealing ability of mineral trioxide aggregate and Biodentine as the root end filling material, using two different retro preparation techniques-an in vitro study. Int J Contemp Dent Med Rev 2015;1:1-6

17 Gagliani M, Taschieri S, Molinari R. Ultrasonic root-end preparation: influence of cutting angle on the apical seal. J Endod 1998;24(11):726-730

18 Gutmann JL, Pitt Ford TR. Management of the resected root end: a clinical review. Int Endod J 1993;26(5):273-283

19 Stropko JJ, Doyon GE, Gutmann JL. Root-end management: resection, cavity preparation, and material placement. Endodontol Topics 2005;11:131-151 
20 Harty FJ, Parkins BJ, Wengraf AM. The success rate of apicectomy. A retrospective study of 1,016 cases. Br Dent J 1970;129(9):407-413

21 Torabinejad M, Higa RK, McKendry DJ, Pittford TR. Effects of blood contamination on dye leakage of four root-end filling materials. J Endod 1994;20:159-163

22 Torabinejad M, Watson TF, Pitt Ford TR. Sealing ability of a mineral trioxide aggregate when used as a root end filling material. J Endod 1993;19(12):591-595

23 Tam A, Yu DC. A new approach to restoring root-end cavity preparation in surgical endodontic procedures-a scanning electron microscopy study. Compend Contin Educ Dent 2002;23(12):1123-1126, 1128, 1130, quiz 1132

24 Vasudev SK, Goel BR, Tyagi S. Root end filling materialsa review. Endodontology 2003;15:12-18

25 Regan JD, Gutmann JL, Witherspoon DE. Comparison of Diaket and MTA when used as root-end filling materials to support regeneration of the periradicular tissues. Int Endod J 2002;35(10):840-847

26 Torabinejad M, Smith PW, Kettering JD, Pitt Ford TR. Comparative investigation of marginal adaptation of mineral trioxide aggregate and other commonly used root-end filling materials. J Endod 1995;21(6):295-299

27 Torabinejad M, Rastegar AF, Kettering JD, Pitt Ford TR. Bacterial leakage of mineral trioxide aggregate as a root-end filling material. J Endod 1995;21(3):109-112

28 Parirokh M, Torabinejad M. Mineral trioxide aggregate: a comprehensive literature review-Part I: chemical, physical, and antibacterial properties. J Endod 2010;36(1):16-27
29 Katge FA, Shivasharan PR, Patil D. Sealing ability of mineral trioxide aggregate Plus ${ }^{\mathrm{TM}}$ and Biodentine ${ }^{\mathrm{TM}}$ for repair of furcal perforation in primary molars: An in vitro study. Contemp Clin Dent 2016;7(4):487-492

30 Arora V, Nikhil V, Sharma N. Bioactive dentine replacement. J Dent Med Sci 2013;12(4):51-57

31 Sheetal M, Amit P, Dhairyasheel E, Amit C, Abhijit P, Rahul SR. Methodologies for assessing root canal sealing: a review. Int J Oral Care Res 2015;3:55-28

32 KokateSR, Pawar AM. An in vitro comparative stereomicroscopic evaluation of marginal seal between MTA, glass ionomer cement \& Biodentine as root end filling materials using 1\% methylene blue as tracer. Endodontology 2012;24:36-42

33 Radeva E, Uzunov T, Kosturkov D. Microleakage associated with retrograde filling after root end resection. J Int Med Assoc Bulgaria 2014;20:578-583

34 P V R, Vemisetty H, K D, et al. Comparative evaluation of marginal adaptation of Biodentine(TM) and other commonly used root end filling materials-an in vitro study. J Clin Diagn Res 2014;8(3):243-245

35 Han L, Okiji T. Uptake of calcium and silicon released from calcium silicate-based endodontic materials into root canal dentine. Int Endod J 2011;44(12):1081-1087

36 Camilleri J, Grech L, Galea K, et al. Porosity and root dentine to material interface assessment of calcium silicate-based rootend filling materials. Clin Oral Investig 2014;18(5):1437-1446

37 Camilleri J, Formosa L, Damidot D. The setting characteristics of MTA Plus in different environmental conditions. Int Endod J 2013;46(9):831-840 